
D:\Nsurg \Vol. 24, No. 2, Apr. - Jun., 2020\Nsurg-4.Doc
Fig. 1-5 Color
(A)
P. $95-101$
III

ORIGINAL ARTICLE

\title{
Insular Glioma Esoteric Precinct
}

\author{
FAUZIA SAJJAD, MUHAMMAD ASIF SHABBIR, MUHAMMAD AKMAL, ZAIN SALEH, \\ ADEEB-UL-HASSAN, IRFAN SHEIKH, MOHSIN NADIR, AMJAD ALI, KAZIM ALI \\ Department of Neurosurgery, Punjab Institute of Neuro Sciences (PINS), Lahore - Pakistan \\ DOI 10.36552/pjns.v24i2.404
}

\begin{abstract}
Background and Objective: The complex insular anatomy and its proximity to eloquent areas make this area almost inaccessible for safe surgical resection of Glioma. Aim of our study is to determine outcome assessment after surgical resection.

Materials \& Methods: This was a retrospective analysis of 59 patients over a period of 5 years from July 2013 till June 2018. All patients of insular Glioma were included in our study irrespective of age and sex. Degree of surgical resection, Post-operative neurological deficits and complications were assessed. They were followed in the outpatient department at 3, 6 and 12 months.

Results: Total 59 patients were included 38 (64.40\%) male and 21 (35.59\%) females. 36 (61\%) patients had right sided insular Glioma and 23 (38.98\%) have left sided. Seizures were main presentation in 46(77.96\%) patients. Trans-sylvian route adopted in $34(57.6 \%)$ patients followed by transcortical route. Near total Resection was Possible in 30 (50.84\%) patients and partial in 29 (49.15\%) patients. Focal neurological deficits the motor weakness \& dysphasia were main post-operative complications in 18 (30.5\%) patients. Three (5.08\%) patients died. In all grade II and grade III Gliomas no increase in size was discovered on MRI Brain at 6 and 12 months.
\end{abstract}

Conclusion: Maximum safe resection of insular Glioma with acceptable morbidity is possible with improved overall survival and disease free interval.

Keywords: Insular Glioma, Approaches to insular Glioma.

\section{INTRODUCTION}

Insula is a real esoteric precinct in human brain. The complex anatomy of insula with unique long and short gyri, the nexus arborized vasculature of perforators and lateral lenticulostriate arteries from MCA, the vicinity of eloquent cortices, and converging motor cortex to internal capsule, uncinate fasciculus, striatum and other critical structures made this functionally significant area intricate. Insular cortex declared jinxed and haunted for many years. ${ }^{1,2}$ In 1992, Yasirgill identified a safe corridor via Trans-sylvian route for resection of lesions of insula. ${ }^{3,4}$ Later on, the fear of damage after resection of lesion dampens gradually. Better understanding of anatomical details of the pyramidal nature of the insula, fenced by anterior, superior and inferior insular sulci, convergence of gyri to insular stem and limen insuli within it made it possible to dare to resect insular lesions ${ }^{5}$. Comprehensive understanding of the origin of ramification of MCA and its perforators, use of modern anesthesia technology, the awake craniotomy, neuro navigation protocol and brain mapping all added to safe excision of the lesion with maximum preservation of vital insular and peri-insular neural connections and with acceptable morbidity. ${ }^{5,6,9}$ Senai proposed a new classification for proper selection of surgical route for different insular lesions according to anatomical location. ${ }^{7,15}$

\section{MATERIALS AND METHODS}

\section{Study Design}

This was a retrospective analytic study. Approval was taken from the Office of Research Affairs. The 
medical record was reviewed retrospectively of 59 insular Glioma patients over a period of 5 years from July 2013 till June 2018. All patients of insular Glioma were included in our study irrespective of age and sex.

\section{Data Collection}

The clinical information, including their age, gender, presenting symptoms, radiological imaging, treatment strategies for surgical excision, post-operative extent of excision, morbidity and mortality and recurrence was analyzed.

\section{Data Analysis}

Data was statistically analyzed by using SPSS version 23. Variables were identified. Simple descriptive statistics were used for analysis of demographic variables. Mean and standard deviations were calculated for age. Frequency and percentages were determined for qualitative variables that is: gender, presenting symptoms, location of lesion, and surgical route for its excision as well as for post-operative complications. All patients were followed in the outpatient department at 3,6 and 12 months.

\section{SurgicalApproaches}

All patients were operated via. the Trans-sylvian or trans-cortical approach.

\section{RESULTS}

Collective data of 59 patients who had undergone insular Glioma surgery during this period was included.

\section{Gender Incidence}

There were 38 (64.40\%) male and 21 (35.59\%) females.

\section{Clinical Features}

$36(61 \%)$ patients had right sided insular Glioma and $23(38.98 \%)$ had Glioma on left sided (see table 3). Our $30(51 \%)$ patients had more than one zone involvement, followed by $21(36 \%)$ patients having single zone involvement, while 8 patients (13\%) hadGlioma in all zones of the insula (see Figure 1).

Seizures were main presentation in 46 (77.96\%) patients, then seizures and motor weakness in 11 (18.64\%) patients (see Figure 2). Near total Resection was possible in $30(50.84 \%)$ patients and partial in 29
(49.15\%) patients (see table 4). Post-operatively, motor weakness was observed in 18 (30.5\%) patients, among them craniotomy flap was removed in 9 $(15.25 \%)$ patients as having severe edema \& midline shift. Five $(8.47 \%)$ patients had dysphasia along motor weakness, only four $(6.77 \%)$ patients had motor weakness without malignant edema \& dysphasia. Tumor bed bleed occurred in $3(5.08 \%)$ patients and wound infection in $2(3.38 \%)$ patients. CSF leakage observed in $2(3.38 \%)$ patients that was managed conservatively (see Figure 4 for complications). Our 3 $(5.08 \%)$ patients died. Overall morbidity was in 25 $(42.37 \%)$ patients (Figure 5).

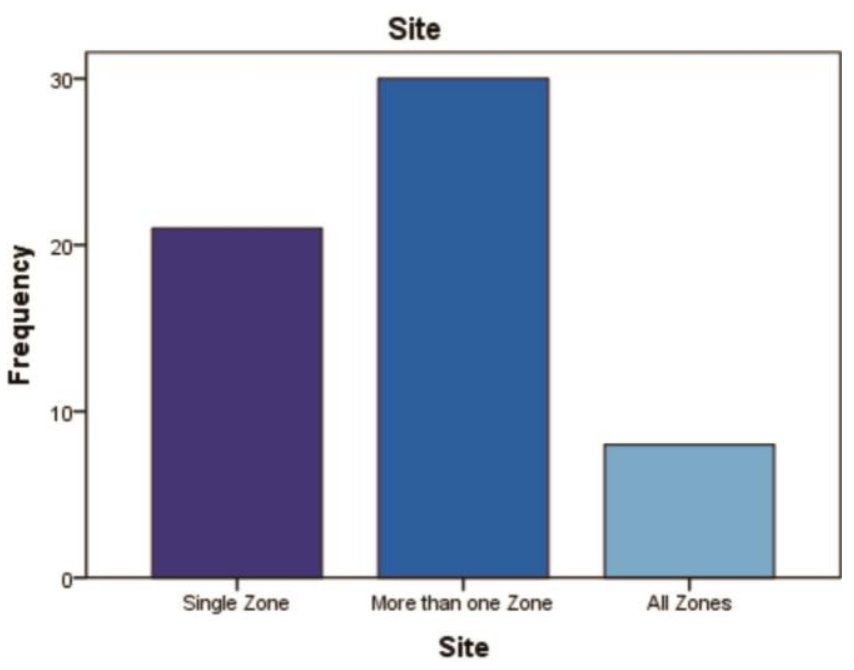

Fig. 1: Zonal Involvement of Tumors.

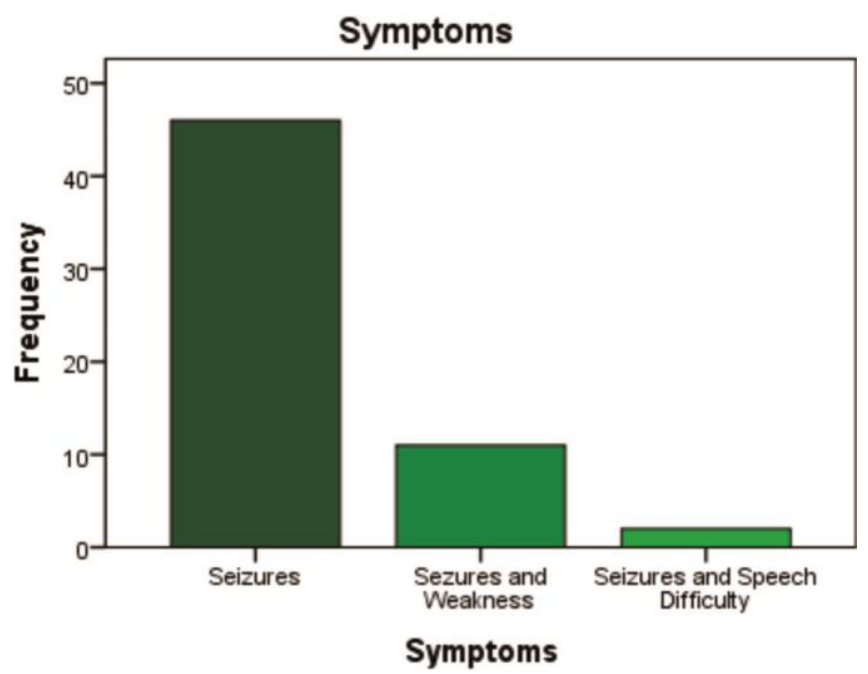

Fig. 2: Presenting Signs and Symptoms. 
Grade II tumor was diagnosed histo-pathologically in $34(50.6 \%)$ patients, Grade III in $13(22 \%)$ and Grade IV in $12(20.3 \%)$ Patients (Table 5). Grade II and grade III Gliomas showed no increase in size on MRI Brain at 6 and 12 months.

\section{Neuroimaging}

For reference, we have included neuroimaging of two cases included in this study. Figure 6: A, B, C, D, \& E showed pre-operative MRI Brain plain and contrast cuts of a 38 year old female who presented with seizures and grade 2 right sided hemiparesis. F shows post operative CT Scan Brain Plain of the same patient after surgery. Her tumor was in two zones. She had no known co-morbids. She was operated via trans cortical (trans opercular) approach and a near total resection was achieved. She remained on same neurological status as pre operative. She was followed in outdoor with no post operative complications. However, her histopathology report turned out to be Glioblastoma Multiforme Grade IV and she was followed accordingly. Figure 7 shows Pre-operative and post-operative MRI Brain plain and contrast and CT brain plain images of a 46 year old female who presented with seizures, right hemiplegia and altered sensorium with a karnofsky score of 50. She had involvement of all four zones. A partial resection was performed in this patient preserving the vascular network. She was operated via trans-sylvian route. Post operatively patient improved initially but then deteriorated later on after she developed pulmonary complications and died of pneumonia on $7^{\text {th }}$ post operative day.
Table 1: Different Age groups.

\begin{tabular}{|l|l|c|c|c|c|}
\hline \multicolumn{2}{|c|}{} & Frequency & Percent & $\begin{array}{c}\text { Valid } \\
\text { Percent }\end{array}$ & $\begin{array}{c}\text { Cumulative } \\
\text { Percent }\end{array}$ \\
\hline \multirow{5}{*}{ Valid } & $20-30$ years & 8 & 13.6 & 13.6 & 13.6 \\
\cline { 2 - 6 } & $30-40$ years & 21 & 35.6 & 35.6 & 49.2 \\
\cline { 2 - 6 } & $41-50$ years & 19 & 32.2 & 32.2 & 81.4 \\
\cline { 2 - 6 } & $51-60$ years & 7 & 11.9 & 11.9 & 93.2 \\
\cline { 2 - 6 } & More than 60 years & 4 & 6.8 & 6.8 & 100.0 \\
\cline { 2 - 6 } & Total & 59 & 100.0 & 100.0 & \\
\hline
\end{tabular}

Table 2: Gender Distribution.

\begin{tabular}{|l|l|c|c|c|c|}
\hline \multicolumn{2}{|c|}{} & Frequency & Percent & Valid Percent & $\begin{array}{c}\text { Cumulative } \\
\text { Percent }\end{array}$ \\
\hline \multirow{3}{*}{ Valid } & Female & 21 & 35.6 & 35.6 & 35.6 \\
\cline { 2 - 6 } & Male & 38 & 64.4 & 64.4 & 100.0 \\
\cline { 2 - 6 } & Total & 59 & 100.0 & 100.0 & \\
\hline
\end{tabular}

Table 3: Side of Tumor.

\begin{tabular}{|c|l|c|c|c|c|}
\hline \multicolumn{2}{|c|}{} & Frequency & Percent & Valid Percent & $\begin{array}{c}\text { Cumulative } \\
\text { Percent }\end{array}$ \\
\hline \multirow{3}{*}{ Valid } & Right & 36 & 61.0 & 61.0 & 61.0 \\
\cline { 2 - 6 } & Left & 23 & 39.0 & 39.0 & 100.0 \\
\cline { 2 - 6 } & Total & 59 & 100.0 & 100.0 & \\
\hline
\end{tabular}

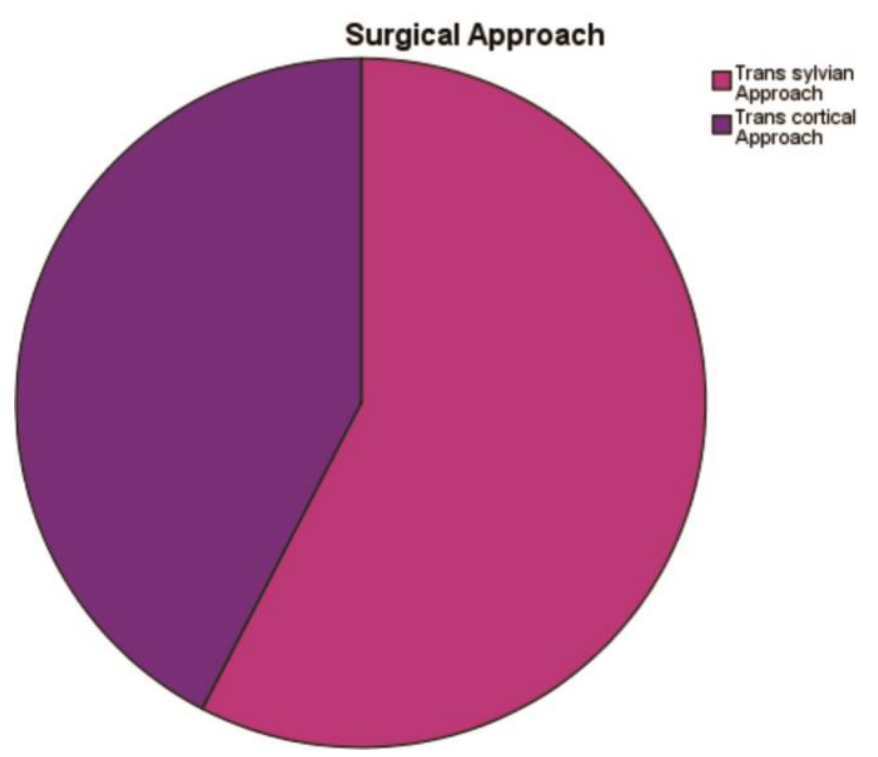

Fig. 3: Surgical Approaches. 
Table 4: Degree of Resection.

\begin{tabular}{|c|l|c|c|c|c|}
\hline \multicolumn{2}{|c|}{} & Frequency & Percent & $\begin{array}{c}\text { Valid } \\
\text { Percent }\end{array}$ & $\begin{array}{c}\text { Cumulative } \\
\text { Percent }\end{array}$ \\
\hline \multirow{3}{*}{ Valid } & Near total & 30 & 50.8 & 50.8 & 50.8 \\
\cline { 2 - 6 } & Partial & 29 & 49.2 & 49.2 & 100.0 \\
\cline { 2 - 6 } & Total & 59 & 100.0 & 100.0 & \\
\hline
\end{tabular}

Table 5: Tumor Grading Via Histopathology.

\begin{tabular}{|c|l|c|c|c|c|}
\hline \multicolumn{2}{|c|}{} & Frequency & Percent & $\begin{array}{c}\text { Valid } \\
\text { Percent }\end{array}$ & $\begin{array}{c}\text { Cumulative } \\
\text { Percent }\end{array}$ \\
\hline \multirow{3}{*}{ Valid } & Grade 2 & 34 & 57.6 & 57.6 & 57.6 \\
\cline { 2 - 6 } & Grade 3 & 13 & 22.0 & 22.0 & 79.7 \\
\cline { 2 - 6 } & Grade 4 & 12 & 20.3 & 20.3 & 100.0 \\
\cline { 2 - 6 } & Total & 59 & 100.0 & 100.0 & \\
\hline
\end{tabular}

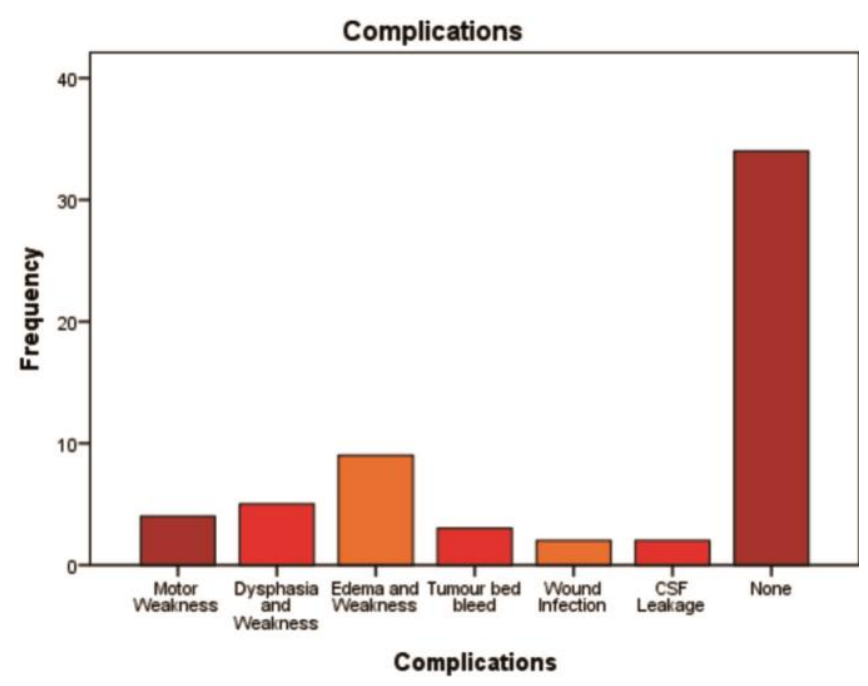

Fig. 4: Frequency of Complications.

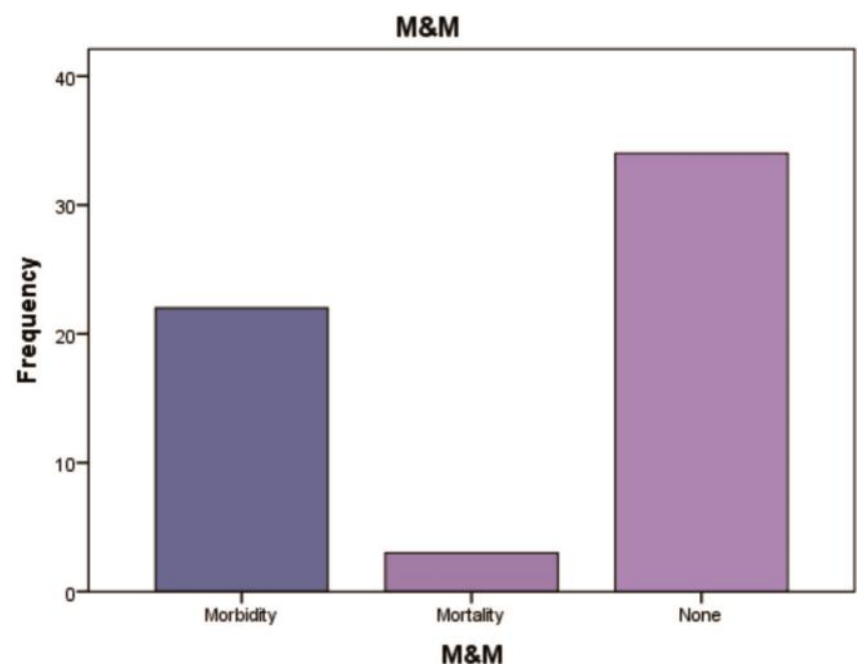

Fig. 5: Frequency of Morbidity and Mortality.

\section{Neuroimaging}

Preoperative and postoperative neuroimaging of two cases were included in this study. 

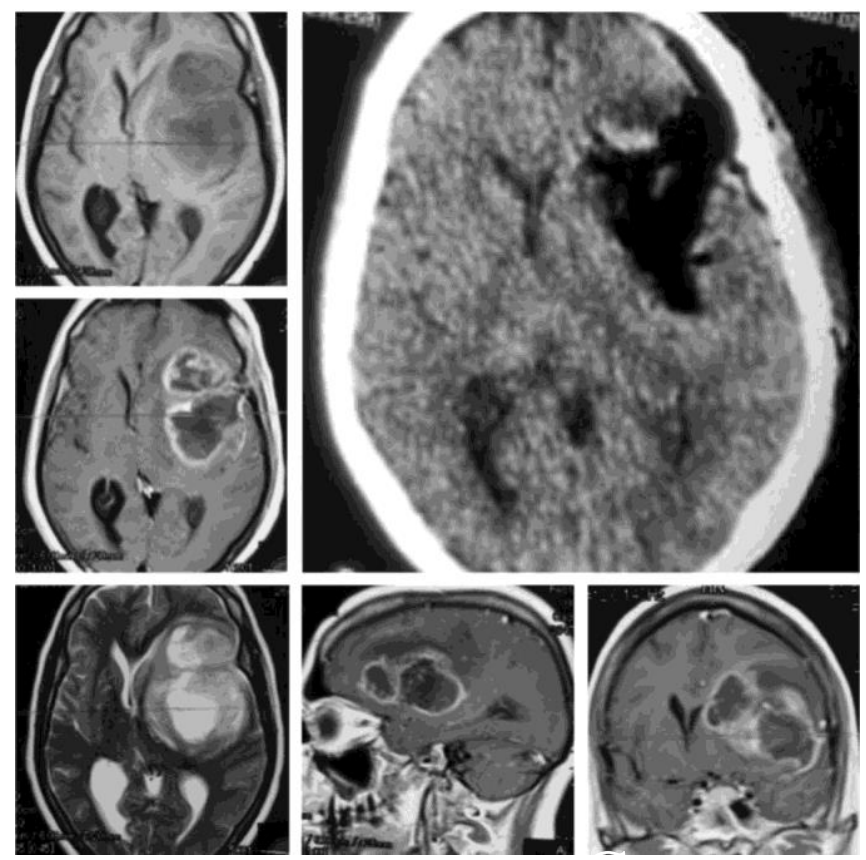

Fig. 6: Above imaging is of 38 years old female who presented with seizures and right sided grade 2 hemiperesis. A, B, C, D, E show pre operative and $F$ shows post operative imaging.
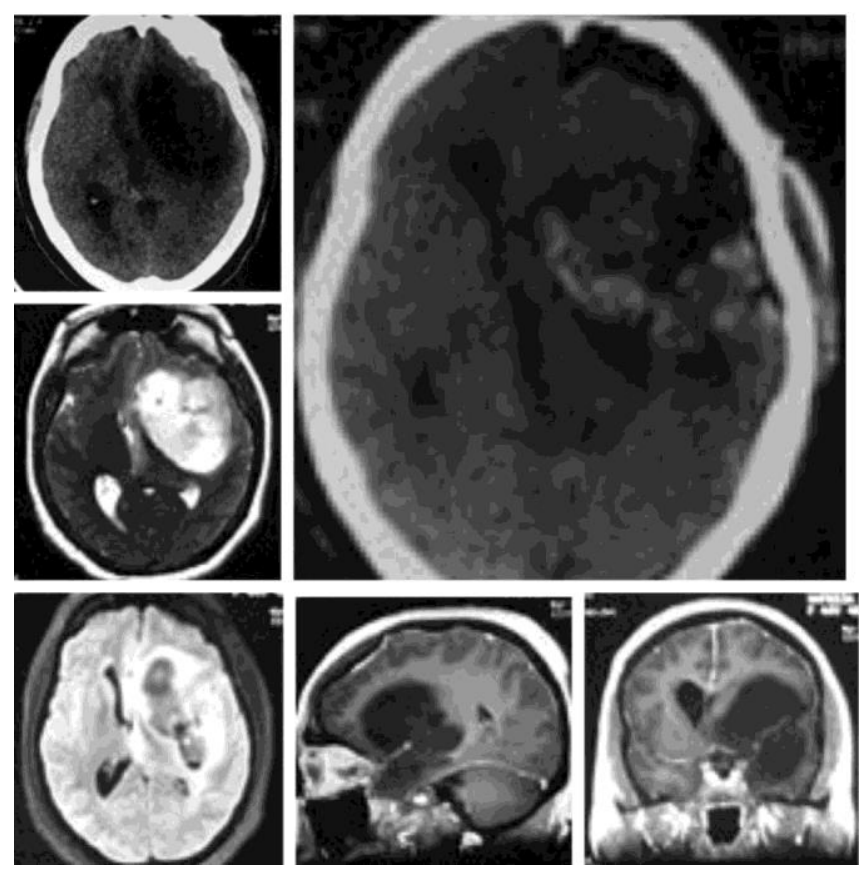

Fig. 7: Shows pre-operative scans A, B, C, D, \& E of a 46 years old female who presented with seizures right sided hemiplegia and altered sensorium with bad Karnofsky score. Whereas $F$ shows post-operative scan of the patient.

\section{DISCUSSION}

The intricate concealed island remained in operable for many years. ${ }^{1,5,7}$ The lesions of this area were accessed later, after understanding of relatively complicated neurovascular anatomy and by adopting specialized microsurgical techniques. ${ }^{3,5,8}$ Insular Gliomas constitute a sizable bulk of brain Gliomas. ${ }^{9}$ Approximately $25 \%$ of low grade Gliomasand $10 \%$ of high grade brain Gliomas reside in insula. ${ }^{10,11}$

In our study, we utilized retrospectively patient's data. All patients included in this study were operated by two surgeons, author one and three. Both having complete understanding of insular anatomy and good command on microsurgical techniques.

In western world and at good neurosurgical institutes, insular Glioma surgery is performed as awake craniotomy with utilization of cortical and sub cortical mapping for identification of eloquent areas of brain. ${ }^{6,12,13}$ Unfortunately, although tertiary care center, but we are lacking such facilities probably due to financial constraints, high traffic of brain tumor patients, departmental politics and corruption. May be in the thickly populated developing countries, the sucker, bipolar and microscope are the only weapons of neurosurgeons.

In our study, the seizure was the most common presenting symptom and in all previous insular Glioma studies, it was the most common. ${ }^{14,15}$ Yasirgill was the pioneer to deal with insular Gliomas with acceptable morbidity, he operated all patients via Trans-Sylvian route. ${ }^{10}$ In our study, weoperated $34(58 \%)$ patientsby Trans-Sylvian route and 25 (42\%) patients by transcortical route. Sinai and burger defined zones for better selection of approach, they operated tumors via Transcortical, Trans-Sylvian and even by the combined approach. ${ }^{7}$ In few past studies, they did not document about the extent of resection. We were able to excise near the total tumor in $30(51 \%)$ patients and in $29(49 \%)$ patients only partial resection was possible. Vanaclocha reported much better results about total excision in $87 \%$ patients, ${ }^{16}$ while Chikezi and Refaey reported only $40 \%$ cases with more than $90 \%$ resection. ${ }^{17}$ We found low grade Gliomas in $58 \%$ patients followed by grade 3 and grade 4 tumors. Przybylowski and Baranoski reported in their cohort study of 100 patients, $68 \%$ high grade and only $32 \%$ low grade Gliomas. ${ }^{18}$ Our results reflect that in Pakistani populations, lower grade Gliomas reside in 
the insula. We noticed $61 \%$ insular Gliomas on the right side and $38 \%$ on left side. While, most of the studies document left sided insular tumors. ${ }^{11,16 .}$

\section{CONCLUSION}

Maximum safe resection of insular Glioma with acceptable morbidity is possible with improved overall survival and disease free interval.

\section{REFERENCES}

1. Kim YH, Kim CY. Current surgical management of insular gliomas. Neurosurg Clin N Am. 2012; 23: 199206vii.

2. Signorelli, Francesco \& Guyotat, Jacques \& Elisevich, Kost \& Barbagallo, Giuseppe. Review of current microsurgical management of insular gliomas. Actaneurochirurgica. 2009; 152. 19-26. 10.1007/s00701-009-0450-y.

3. Yasargil MG, Kasdaglis K, Jain KK, et al. Anatomical observations of the subarachnoid cisterns of the brain during surgery. J Neurosurg. 1976; 44: 298-302.

4. Yasargil MG, Krisht AF, Türe U, et al: Microsurgery of insular gliomas: Part I, II, IV. Contemporary Neurosurgery, 1976; 24: (11): 1-8.

5. Benet A, Hervey-Jumper SL, Sánchez JJ, Lawton MT, Berger MS. Surgical assessment of the insula. Part 1: surgical anatomy and morphometric analysis of the trans-sylvian and transcortical approaches to the insula. J Neurosurg. 2016; 124: 469-481.

6. Alimohamadi M, Shirani M, Shariat Moharari R, PourRashidi A, Ketabchi M, Khajavi M. Application of awake craniotomy and intraoperative brain mapping for surgical resection of insular gliomas of the dominant hemisphere. World Neurosurg. 2016; 92: 151-158.

7. Sanai, N., M.Y. Polley, and M.S. Berger, Insular gliomare section: assessment of patient morbidity, survival, and tumor progression. J Neurosurg. 2010; 112 (1): 1-9.

8. Barbosa BJ, Dimostheni A, Teixeira MJ, Tatagiba M, Lepski G. Insular gliomas and the role of intraoperative assistive technologies: results from a volume try-based retrospective cohort. Clin Neurol Neurosurg. 2016; 149: 104-110.

9. Duffau, H. and L. Capelle, Preferential brain locations of low-grade gliomas. Cancer, 2004; 100 (12): 26222626.

10. Yasargil, M.G., Tumours of the limbic and paralimbic systems. Acta Neurochir (Wien), 1992; 118 (1-2): 4052.

11. Ebeling U, Kothbauer K. Circumscribed low grade astrocytomas in the dominant opercular and insular region: a pilot study. Acta Neurochir (Wien). 1995; 132: 66-74.

12. Duffau H, Moritz-Gasser S, Gatignol P. Functional outcome after language mapping for insular World Health Organization Grade II gliomas in the dominant hemisphere: experience with 24 patients. Neurosurg Focus, 27 (2) :E72009.

13. Gravesteijn BY, Keizer ME, Vincent AJPE, Schouten JW, Stolker RJ, Klimek M. Awake craniotomy versus craniotomy under general anesthesia for the surgical treatment of insular glioma: choices and outcomes. Neurol Res. 2018; 40: 87-96.

14. Duffau, $\mathrm{H}$, The insular lobe: physiopathological and surgical considerations. Neurosurg 2000; 47 (4): 80110 .

15. Hervey-Jumper S, \& Berger, MS. Insular glioma surgery: an evolution of thought and practice, Journal of Neurosurgery JNS. 2019; 130 (1): 9-16.

16. Vanaclocha, V., N. Saiz-Sapena, and C. GarciaCasasola, Surgical treatment of insular gliomas. Acta Neurochir (Wien), 1997; 139 (12): 1126-34.

17. Eseonu, Chikezie \& Refaey, Karim \& Raghuraman, Gugan \& Quiñones-Hinojosa, Alfredo. 378 Analysis of Molecular Markers and Volumetric Extent of Resection on Survival for Insular Gliomas. Neurosurgery. 2017; 64: 289-290. 10.1093/neuros/nyx417.378.

18. Przybylowski CJ, Baranoski JF, So VM, Wilson J, Sanai N. Surgical morbidity of transsylvian versus transcortical approaches to insular gliomas. J Neurosurg. $\quad 2019 ; \quad 5: 1-8$. Doi: 10.3171/2018.12.JNS183075.

\section{Additional Information}

Disclosures: Authors report no conflict of interest.

Ethical Review Board Approval: The study was conformed to the ethical review board requirements.

Human Subjects: Consent was obtained by all patients/participants in this study.

Conflicts of Interest:

In compliance with the ICMJE uniform disclosure form, all authors declare the following:

Financial Relationships: All authors have declared that they have no financial relationships at present or within the previous three years with any organizations that might have an interest in the submitted work.

Other Relationships: All authors have declared that there are no other relationships or activities that could appear to have influenced the submitted work. 


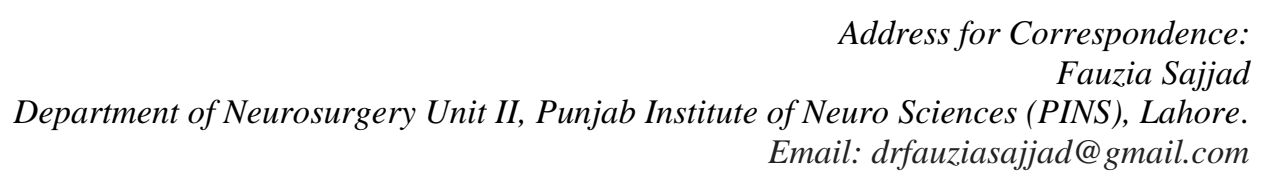

AUTHORSHIP AND CONTRIBUTION DECLARATION

\begin{tabular}{|c|c|c|}
\hline Sr.\# & Author's Full Name & Intellectual/Contribution to Paper in Terms of: \\
\hline 1. & Fauzia Sajjad & $\begin{array}{l}\text { 1. Proposed Topics and Basic Study Design, Methodology, } \\
\text { Manuscript Writing. }\end{array}$ \\
\hline 2. & Muhammad Asif Shabbir & 2. Literature Review, Data Collection and Calculations. \\
\hline 3. & Muhammad Akmal & $\begin{array}{l}\text { 3. Analysis of Data, Literature Review and Manuscript } \\
\text { Writing. }\end{array}$ \\
\hline 4. & Zain Saleh & $\begin{array}{l}\text { 4. Literature Review and Manuscript Writing, Paper } \\
\text { Writing. }\end{array}$ \\
\hline 5. & Adeeb-ul-Hassan & 5. Paper Writing, Literature Review. \\
\hline 6. & Irfan Sheikh & 6. Paper Writing. \\
\hline 7. & Mohsin Nadir & 7. Literature Review. \\
\hline 8. & Amjad Ali & 8. Data Collection and Calculations. \\
\hline 9. & Kazim Ali & 9. Data Collection. \\
\hline
\end{tabular}

Date of Submission: 4-4-2020

Date of Revision: 12-04-2020

Date of Online Publishing: 30-06-2020

Date of Print: 30-7-2020 